\title{
LA PRUEBA FINANCIERA EN LA JURISPRUDENCIA SOBRE EL DELITO DE TRATA DE PERSONAS
}

\section{Financial Evidence in Jurisprudence on the Crime of Trafficking in Persons}

\author{
Luis Lafont Nicuesa \\ Fiscal. Unidad de Extranjería de la Fiscalía General del Estado \\ E-mail: luis.lafont@fiscal.es
}

La investigación financiera del delito de trata de personas va adquiriendo gradualmente una mayor importancia. Puede configurar delitos específicos como el de blanqueo de capitales o contra la hacienda pública, medidas accesorias como el decomiso y perfilar una contundente prueba indiciaria que avale la prueba testifical de la víctima asegurando así la correspondiente condena. En este trabajo además de dar unas pautas generales sobre el concepto e importancia de la investigación financiera vamos a analizar las diferencias en la financiación entre las redes de trata y de inmigración ilegal, así como los aspectos que están tomando en consideración los tribunales en el ámbito financiero para dar crédito al testimonio de la víctima.

The financial enquiry of human trafficking crime is increasingly gaining bigger relevance. It may constitute a specific crime as money laundering or a tax evasion crime, may allow accessory measures as seizure and outline conclusive circumstantial evidence, ratifying victim's testimony and ensuring in this manner the consequent conviction. In this paper, in addition to give some general rules about the concept and importance of financial enquiry, the differences of funding between buman trafficking and illegal immigration will be examined as well as the factors the Courts are taking into account in the financial sphere to bring credibility to victim's testimony.

negocio; indicio; dinero; patrimonio; justificación business; circumstantial evidence; money; property; excuse

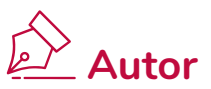

(1) Resumen

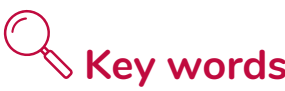
Fechas 


\section{La trata de seres humanos como actividad empresarial lucrativa}

La Resolución del Parlamento Europeo (2016) de lucha contra la trata en las relaciones exteriores de la Unión califica la trata como “...una de las actividades delictivas organizadas más rentables del mundo, junto al comercio de drogas ilegales y de arma... la trata de seres humanos es un negocio extremadamente lucrativo". El delito gira todo él en torno al dinero. Los grandes beneficios que reporta esta actividad, así como el bajo riesgo de detección y castigo, hacen de esta una empresa sumamente productiva, tentadora y generadora de ingentes ganancias. La investigación patrimonial y la adopción de medidas cautelares de naturaleza financiera fundamentalmente el bloqueo preventivo de cuentas y depósitos resulta fundamental para una persecución eficaz del delito. La trata es, básicamente, un negocio criminal en auge y como tal hay que afrontar la lucha contra él (Fernández Olalla, 2015, pp. 7-8).

Efectivamente, la trata de seres humanos es una actividad de una alta rentabilidad económica ya que el producto que comercializa, a diferencia de la droga, es el ser humano que no se consume en su primera utilización, sino que se emplea de manera indefinida en el tiempo generando una fuente estable de beneficios.

Debe también tenerse en cuenta que algunas organizaciones de trata como las nigerianas, junto a la explotación de la víctima, tienen divisiones negociales paralelas como los matrimonios de conveniencia o el clonado de tarjetas de crédito que a veces compiten en rentabilidad con la actividad de explotación sexual. Así, la Sentencia de la Audiencia Provincial de Barcelona de 15 de septiembre de 2014 recoge cómo los tratantes concertaban matrimonios de conveniencia o parejas de hecho para las víctimas. Con ello, además de lograr que la víctima no pueda ser expulsada constituía, una importante fuente de recursos económicos. Ofrecían a la pareja española entre 700 y 1000 euros y cobran a la víctima 6.000 euros por el servicio prestado para regularizarla. Asimismo, la organización llevaba a cabo una actividad delictiva de clonado de tarjetas de crédito que ofrecía importantes recursos económicos.

El objetivo de la investigación financiera para el Parlamento Europeo es claro cuando pide a los Estados miembros que transformen la trata de seres humanos — que constituye actualmente una actividad de bajo riesgo y alta productividad — en una actividad de alto riesgo y baja productividad. En definitiva, se trata de arruinar a la trata y para ello es preciso desplegar una actividad investigadora financiera y patrimonial global que quite a los tratantes su dinero y bienes para revertirlo sobre las víctimas.

\section{Concepto de investigación financiera y su importancia probatoria}

El Consejo General del Poder Judicial (2018, p. 188) define la investigación financiera como el "Conjunto de actuaciones policiales y judiciales encaminadas a elaborar el catálogo nominal y real de bienes y derechos de una o varias personas físicas o jurídicas, estableciendo su posible origen y su proceso de formación".

Podemos definir la investigación financiera como la acción policial dirigida a reunir información y evidencias sobre las fuentes de riqueza de los tratantes y su circulación interior y exterior, fijando un nexo causal con su actividad criminal de trata y explotación con la 
finalidad de detectar delitos autónomos como el blanqueo, facilitar el decomiso y obtener evidencias incriminadoras para probar la trata.

Naciones Unidas (2009, p. 104) ha insistido en cómo la trata de personas es un proceso comercial donde los seres humanos son comprados y vendidos. El objetivo de toda investigación por los oficiales de investigación debe consistir en lograr no solo que determinados delincuentes sean declarados culpables, sino también, desarticular las redes. El seguimiento de las fuentes de financiación de las redes y su posterior incautación producen un grave daño a este tipo de actividad criminal que gira alrededor de tratos, ganancias y poder.

Para Naciones Unidas (2007, pp. 80-81) la trata orbita en torno al flujo y circulación del dinero. Además de la inversión inicial para crear la infraestructura y entregar a las víctimas para su explotación, la gestión continua del producto de esa explotación y, finalmente, el blanqueo y el movimiento de las ganancias forma parte de las actividades de los traficantes. Por ello, (2009, pp. 108-109) destaca la necesidad de la rapidez, aconsejando llevar a cabo una investigación financiera previa antes de que haya detenciones. También se resalta la importancia del acceso a los archivos económicos de las redes. La trata de personas es un proceso comercial y, como ocurre en cualquier tipo de empresa, lleva registros. Estos archivos resultan a menudo muy valiosos para los investigadores. Algunos de los documentos importantes que pueden encontrarse en las investigaciones de casos de trata de personas son: cuentas del dinero recaudado en prostíbulos u otras empresas ilegales, extractos de cuentas bancarias y detalles de operaciones no estructuradas (sistemas del tipo Hawala)..., anotaciones de facturas pagadas en concepto de publicidad, detalles de las tarjetas de crédito de los clientes, dinero en efectivo, documentos que indiquen el volumen de negocio en un lugar determinado, como el material entrante y las mercancías terminadas.

Las jornadas de Fiscales Delegados de Extranjería (2012 y 2016) han recalcado que la investigación de los mecanismos financieros de las redes esclavistas es clave y debe estar presente desde un principio en la investigación policial. Para los fiscales "se debe promover la investigación patrimonial eficaz, desde los primeros momentos, en coordinación con la policía y, en su caso, con los organismos especializados en la prevención del blanqueo". La Fiscalía debe supervisar que la investigación policial ofrezca una radiografía de la estructura criminal en cuanto a los beneficios que ha obtenido. "Los Fiscales delegados de extranjería velarán porque en la fase de instrucción de las causas por delitos de trata de seres humanos y prostitución coactiva, la investigación se extienda a una rigurosa valoración sobre el rendimiento económico obtenido de la explotación de las víctimas, significadamente en el ámbito de los locales, clubes o establecimientos abiertos al público donde se desarrollan actividades de alterne o/y otros servicios sexuales".

Otro de los pilares es la necesaria coordinación de la Fiscalía de Extranjería con los fiscales de delitos económicos. Así, una de las conclusiones de las jornadas de Fiscales Delegados de Extranjería (2012) es que "Los fiscales delegados de extranjería se coordinarán con los fiscales especializados en delitos económicos para la persecución de los delitos patrimoniales cometidos en la explotación de negocios relacionados con el comercio sexual". También prevé la necesidad de designar un Fiscal Delegado de Extranjería en la Fiscalía anticorrupción. Las memorias de la Fiscalía (2015 y 2017) han incidido de manera constante en la importancia de contar en la instrucción de estas causas con un informe de investigación patrimonial. El Defensor del Pueblo (2012, p. 274) lamenta cómo la prueba de la trata sigue dependiendo casi en exclusiva de las declaraciones de las víctimas, pero recalca cómo la investigación financiera efectiva constituye una herramienta importante para la obtención 
de pruebas, la evaluación de los riesgos, para aumentar el conocimiento del modus operandi de los autores de delitos relacionados con la trata de personas y perfeccionar los elementos de detección.

Dentro de su valor probatorio, deben distinguirse dos manifestaciones. La prueba financiera como mecanismo para reforzar la declaración de la víctima y como instrumento para poner de manifiesto otros delitos distintos a la trata como pueden ser el blanqueo o contra la Hacienda Pública. Para acreditar otros delitos son precisas unidades policiales especializadas en el ámbito financiero y complejas investigaciones. En cambio, para generar un indicio no es precisa tal especialización. Basta con localizar cantidades de dinero o bienes pertenecientes al investigado que este no justifique.

El Consejo General del Poder Judicial (2018, p. 132) recalca la importancia de la prueba financiera ya que “...puede servir de apoyo a la causa en caso de que la declaración de la víctima no diera el resultado pretendido o necesitase ser validada mediante elementos periféricos de corroboración... De los flujos y movimientos patrimoniales descubiertos se pueden obtener, además, importantes elementos de corroboración periférica del delito de trata investigado con carácter principal".

Lo normal es que la prueba financiera opere como un elemento que refuerza la declaración de una víctima, pero en casos muy puntuales y con la concurrencia de otros indicios puede llegar a suplirla. Así ocurre en la SAN, secc. 4. ${ }^{\text {a }}, \mathrm{n} .1 / 2019$, de 18 de febrero en que la negativa de una víctima a declarar por miedo se salvó con la declaración de las demás testigos y de los agentes de la Ertzaina que reflejan el miedo de la víctima a la hora de denunciar, pero también los informes económico-financieros supusieron un indicio claro de la esclavitud a la que fue sometida. Es también de gran interés la SAP de Sevilla, secc. 2. ${ }^{\text {a }}$, n. 21/2020, de 5 de mayo. En este caso, la prueba financiera es, junto a un testigo protegido, la principal fuente probatoria ya que la víctima negó los hechos y no reconoció ser tal víctima. La Sala relata como entre el 20 de marzo y el 28 de septiembre de 2017, la acusada ingresó en efectivo y mediante transferencia la cantidad de 19.330 euros, sin que sus ingresos lo justificaran.

\section{Diferencia entre la financiación de las redes de trata e inmigración ilegal}

En el delito de trata, la red se financia con los beneficios derivados de la explotación y de actividades criminales colaterales. A la víctima se le impone una deuda desproporcionada en concepto de manutención, alojamiento, gastos de documentación y de viaje que solo puede pagar aceptando la explotación. La deuda es un pretexto para someter a la víctima y esclavizarla. En el delito de inmigración ilegal, la estructura obtiene su beneficio económico como consecuencia de la deuda derivada de un contrato de transporte y eventualmente otros servicios que concierta con el inmigrante como puede ser la realización de gestiones para la regularización del inmigrante. Como señala la STS n. 214/2017, de 29 de marzo recogiendo una jurisprudencia anterior "En el supuesto de la trata de personas, la fuente principal de ingresos para los delincuentes y el motivo económico impulsor del delito es el producto obtenido con la explotación de las víctimas en la prostitución, trabajos forzados, extracción de órganos u otras formas de abuso; mientras que en el caso de la inmigración ilegal, el precio pagado por el inmigrante irregular, cuando se realiza en el subtipo agravado de ánimo de lucro, es el origen de los ingresos...". 
Señala el Supremo que "no suele mantenerse ninguna relación persistente entre el delincuente y el inmigrante una vez que éste ha llegado a su destino". Sin embargo, en la práctica el contacto entre el delincuente y el inmigrante se mantiene con frecuencia una vez que el segundo ha cruzado nuestras fronteras. El precio se pacta antes de la salida del inmigrante, pero no se abona de forma inmediata, sino que se produce una vez que el inmigrante está en España. Dicho pago se realiza con lo que el inmigrante gana en España a través de diversas actividades.

Cuando en la inmigración ilegal, el dinero con el que la inmigrante paga al traficante procede del ejercicio de la prostitución, las líneas entre trata e inmigración se muestran difusas. La SAP de Sevilla, secc. 4. ${ }^{a}$, n. 328/2017, de 4 de julio aborda la cuestión de la diferencia entre el beneficio de la trata derivado de la explotación de la víctima y el de la inmigración ilegal procedente de un ejercicio voluntario de la prostitución por parte de la víctima. La Fiscalía acusaba por trata y la Sentencia absuelve por dicho delito y condena por inmigración ilegal. Parte para ello de que el origen del dinero le resulta indiferente al contrabandista de personas a quien le da igual que la deuda se abone con dinero derivado de la prostitución de la inmigrante, procedente de familiares o de otras fuentes y si no tiene dinero, el contrabandista sin haberlo planificado previamente, puede sugerir a la inmigrante el ejercicio de la prostitución, pero no va a coaccionarla ni a controlar tal actividad que será ejercida libremente por la inmigrante. El autor de la inmigración ilegal se limitará a recibir el dinero “... esa inducción al ejercicio a la prostitución deriva de la ausencia de otros medios económicos con los que hacer frente al pago, pero surge en un momento posterior y no entraña la explotación como tal de la víctima, a la que se permite ejercer la prostitución en el modo y manera que ella estime, siempre y cuando pague la deuda, pero sin ejercer sobre la misma un férreo y directo control que la mantenga explotada en esa situación con independencia del pago por su traslado irregular a España”. En el mismo sentido, SAP de Sevilla, secc. 4. a, n. $1881 / 2018$, de 5 de noviembre "de la vigencia de la norma, que ya hemos indicado, en todo caso creemos que nos llevaría a apreciar el delito de inmigración ilegal el que la organización en que se integra la acusada pretende obtener sus beneficios mediante la elevada deuda por el traslado cuyo pago se impone a las víctimas, siendo indiferente el origen del dinero, de tal manera que la explotación como tal no integra su propósito inicial, destacando, como ya hacíamos en nuestra sentencia de 4 de julio de 2017”.

\section{El patrimonio invisible}

Cuando en la investigación policial no se encuentran bienes ni dinero en manos de esta organización, las defensas inciden en lo contradictorio que resulta sostener por una parte que estamos ante un delito que produce muy importantes beneficios pero que no se haya encontrado líquido o patrimonio alguno. Es por tanto importante que en estos casos se explique al órgano judicial las razones de tal aparente contradicción.

La STS n. 178/2016, de 3 de marzo, en que resultaron condenados miembros de la organización nigeriana de trata (Supreme Eiye), recoge como no se han encontrado ingentes cantidades de dinero ni se ha detectado un patrimonio suntuario o revelador de tales ilícitas actividades. Y ello se justifica por el testimonio de los mossos que en juicio explicaron como se trataba de un beneficio que emigra a Nigeria a través de un sistema que no deja rastro como es el de la Hawala. Se basa en un fuerte código del honor entre personas de un mismo círculo familiar o social cerrado con numerosos contactos en los que se tiene 
total confianza a través de los que se realizan los pagos y envíos por medio de un código de verificación. En definitiva, es un sistema de compensación. Constituye una alternativa de transferir fondos más baratos que acudir al de las empresas de envío de dinero oficiales y la finalidad perseguida es la opacidad, no dejar rastro ni vestigio alguno del envío del dinero. También, en el caso resuelto por la SAP de Valencia, secc. 2. ${ }^{a}$, n. 157/2016, de 30 de marzo se expone "El hecho de que la investigación patrimonial no detecte dinero del acusado en España no es contradictorio con la manifestación policial de que las redes de trata acumulen grandes beneficios económicos por cuanto como señala el informe policial ello no supone que el beneficio sea en España, siendo factible que ese dinero se oculte y envíe fuera de España”. En dicho procedimiento una testigo señala que una de las acusadas ha comprado una casa en Nigeria.

La consecuencia es clara. Resulta preciso potenciar los mecanismos de cooperación internacional adecuados para acceder a las estructuras financieras de estas redes.

\section{Aspectos económicos valorados por la doctrina judicial}

Examinaremos a continuación las distintas fuentes financieras que se alegan ante los tribunales. Podemos hacer la siguiente división.

\subsection{Documentación bancaria que revela movimientos de dinero no justificados}

Se incluye en este apartado aquellos documentos procedentes de entidades de crédito que reflejan un movimiento de dinero que el acusado no justifica fehacientemente. La STS n. 17/2014, de 28 de enero, considera que corrobora la ilícita actividad de los acusados la documental relativa a los envíos y recibos de dinero "Destacando la existencia de evidencias que corroboran, su ilícita actividad como son la documental existente relativa a los envíos de dinero (57.952,61 Marisol y 13.044,61 E Anton), y recibos de dinero (24.515,08 E y 2.648 Anton) a diversos países de estos acusados, a través de la Western Unión". Del mismo modo, la STS n. 482/2016, de 3 de junio establece "Por último la diversa documentación bancaria ocupada en su domicilio y que pone de relieve una disponibilidad de dinero por su parte muy superior a la que pudiera proceder de su actividad laboral como asalariada". En el ATS de 8 de mayo de 2014 (RC 10167/2014) se valora un exhaustivo informe policial de todas las cuentas de la acusada algunas de las cuales reflejan cantidades excesivas "La declaración testifical se ha visto corroborada igualmente por la existencia de ingresos monetarios en sus cuentas atribuibles a este negocio... Declaración testifical del agente de policía n. ${ }^{\circ}$ NUM001, que elaboró un informe sobre las 15 cuentas corrientes de los acusados. La recurrente tenía 4 de ellas, con numerosas imposiciones en efectivo de pequeñas cantidades, cuyas sumas anuales resultaban excesivas para una persona no cualificada". La Sentencia de la Audiencia Nacional, secc. 4. ${ }^{\text {a }}$, n. $1 / 2015$, de 26 de enero destaca como en las cuentas de la acusada figuran ingresos y transferencias por importe de 286.466,28 euros.

También puede citarse la detallada SAP de Castellón, secc. 2. ${ }^{\text {a }}$ n. 101/2018, de 5 de abril que pone de manifiesto la existencia de numerosas cuentas de los tratantes a nombre de sus hijos y múltiples ingresos que se individualizan en la Resolución "Por otro lado constan numerosas cuentas abiertas en diferentes entidades bancarias, y constan en las mismas va- 
riados ingresos en efectivo que no están justificados... El resto de cuentas, con numerosos ingresos en efectivo pequeños, y retiradas, y a nombre de sus hijos, no se ven justificadas".

Para la Sala este dinero no puede atribuirse a una actividad laboral acreditada de los tratantes. Aunque los acusados atribuyen los ingresos a una actividad laboral, el dinero de las nóminas va a unas cuentas distintas de aquellas en las que está el dinero no justificado. Señala el Tribunal como existen cuentas abiertas en las que se ingresan las nóminas del tiempo en que la acusada trabajó en Marina D’Or y el finiquito por 10.565 euros que el acusado recibió de la compañía Balaguer en la que estuvo trabajando, pero tal ingreso "nada tiene que ver con la pluralidad de movimientos en dinero B que el matrimonio ingresaba en las otras cuentas bajo la identidad de sus hijos".

No tuvo éxito el argumento de las defensas de que tales ingresos en B procedían de una actividad negocial de compra venta de productos nigerianos. El Tribunal concluye que el negocio invocado es una mera ficción. Por un lado, la dinámica negocial que se describe no es razonable "Esta situación de generación de ingresos pequeños múltiples en efectivo ha de ponerse en relación con el alegato de los acusados en la vista oral de que se dedicaba a comprar por encargo a compatriotas nigerianos, que les eran pagadas poco a poco y en dinero que traían encima amigos en los viajes. En verdad no parece razonable un flujo de amistades viajeras que pudieran corresponderse con tanto ingreso; queda por inverosímil la explicación". Por otro lado, una actividad legal debe tener un soporte financiero transparente sin mecánicas de ocultación como es ingresar el dinero en cuentas que están a nombre de los hijos "Y además si se tratara de un actividad transparente y lícita no tenía por qué seguirse una mecánica o estructura de ocultación como es ocuparse en meter dinero poco a poco, pero de forma constante, y en cuentas abiertas a sus hijos menores que ellos manejaban, ocultando la realidad de sus ingresos. Lo que parece indicar una idea de aparentar a modo de tapadera, una actividad mercantil, que difiere de los ingresos que las c/c bancarias reflejan". Asimismo, las facturas que se presentan de la hipotética mercantil nigeriana revelan unos ingresos manifiestamente insuficientes para sostener a los tratantes y su familia "Si se analizan las facturas elaboradas por los acusados que han sido presentadas, tres se refieren a primeros del año 2014 por importes muy discretos de 423,50 euros, 910 euros y 250 euros. Las facturas del año 2013 son de 800, 1600, 1195, 780, 800 y 1400 euros. Las otras facturas, las del año 2102 son solo cuatro (tres de estas fechadas en septiembre) por importes de 1560, 950, 900 y 850 euros. Aparte de que parece poca cantidad de rendimientos, si se deducen de tales precios los costes de adquisición (¿y almacenaje?) de los artículos de segunda mano que adquirían y revendían, para sostener una familia de cuatro hijos y una hipoteca cómo tenían". A ello se une que la documentación de la sociedad nigeriana deja de existir en el momento en que son detenidos "Curiosamente a partir de marzo de 2014 no hay más facturas, como si el descubrimiento de los hechos hubiera paralizado la actividad de la mercantil cuando sin embargo Pio no estuvo privado de libertad". Por último, la Audiencia castellonense reprocha como la inactividad de la defensa que presenta la documentación en forma tardía y el silencio de los acusados ha impedido contrastar la realidad de la mercantil "De hecho los procesados constan como insolventes en la pieza respectiva porque a través de la causa no se ha hallado actividad mercantil, laboral o profesional que pudiera indicar lo contrario. Las defensas durante tres años parece que no estuvieron interesadas en alegar y acreditar lo contrario... la defensa no ha dado oportunidad de contrastar la realidad de tal mercantil, su rastro fiscal, y la autenticidad de las facturas que también tienen apariencia de albaranes de entrega, pues su aportación, clausurada la larga instrucción, en el último momento, junto con el silencio constante de los procesados, ha evitado la investigación sobre 
el particular". Efectivamente, el carácter cuasi sorpresivo de la alegación de la sociedad y la presentación de la documentación en que se sustenta son datos que operaron en contra de dar crédito a su existencia.

Por el contrario, la STS n. 770/2016, de 16 de noviembre no acepta el indicio por cuanto el dinero que figura en las cuentas "se trata de unos ingresos aislados en un conjunto de ellos a lo largo de los años que tienen relación directa con las nóminas cobradas y la mayoría son de cantidades mínimas". Para el Tribunal se ha acreditado a través de los contratos de trabajo una actividad laboral real lo suficientemente intensa para justificar los ingresos de dinero "De la organización dedicada al tráfico de seres humanos y a la explotación coactiva de terceras personas, no consta más dato que la manifestación de la denunciante, pues si se trata de un negocio lucrativo, tal y como se pone manifiesto en el atestado, el acusado ha acreditado que tiene dos trabajos como mozo de almacén o mozo de transportes, que cumple un amplísimo horario laboral con hasta 65 horas semanales, ...y ello se deduce de los contratos de trabajo aportados y de su vida laboral donde se le han cuantificado 19 años de trabajo en España, si bien los reales son 13 porque ha trabajado en muchas ocasiones en dos empresas distintas y ha cotizado a la Seguridad Social por ambas. No se observa ni se acredita el negocio tan lucrativo que se dice por las acusaciones, sino más bien una persona que trabaja un número de horas muy elevado y que cobra dos salarios por ello". Los únicos ingresos que resultan excesivos se producen cuando la testigo supuestamente explotada ha denunciado los hechos por lo que no puede vincularse a una actividad "Es cierto que existen unos ingresos en junio, julio y agosto de 2010 que son superiores a lo habitual llegando incluso el 2 de agosto de 2010 a la cantidad de 2.000 euros, pero a partir de ahí la cantidades disminuyen llegando incluso a ser de 50 euros, sin que dichas cantidades superiores en esos meses de 2010 se puedan relacionar con los hechos denunciados, pues se supone que la denunciante ya vivía con su novio y no se ha acreditado que los acusados pudieran estar explotando sexualmente a otras personas".

Es importante señalar que lo relevante a efectos probatorios es identificar un dinero perteneciente al acusado cuyo origen no justifica. No es preciso que la acusación vincule dicho dinero con la concreta cantidad que la víctima manifiesta haber pagado. Si señala que ha pagado periódicamente cantidades de 300 euros al acusado, no es necesario que la investigación localice ingresos en las cuentas de tratantes de 300 euros. La prueba financiera no es principal sino un indicio que va a complementar la declaración de la víctima por lo que no tiene que entrar en excesivos detalles. Por supuesto que si se localizan ingresos bancarios del tratante que se corresponden con los pagos relatados por la víctima, la entidad probatoria del indicio será superior pero la mera acreditación del ingreso sirve como indicio probatorio.

No comparto por tanto el criterio de la SAP de Valencia, secc. 2. ${ }^{a}$, n. 161/2019, de 25 de marzo, que no da valor a la prueba financiera por cuanto solo un ingreso se corresponde con la cantidad que la víctima dice haber pagado al tratante. En dicho caso, la Policía Nacional aportó un extracto bancario con resguardos de numerosos ingresos. La Sala recoge que dichos ingresos oscilan entre 50 y 600 euros que algunos meses alcanzan los 8.000 euros con otros periodos de tiempo de completa inactividad pero que solo uno de dichos extractos confirma la declaración de la víctima cuando señala que ingresó en la cuenta de acusada 800 euros. El resto del dinero ingresado no coincide en las cantidades referidas por la víctima. Sobre esta base, la Sala estima "...que no ha existido 'estudio sobre significado de claves, origen y una mínima investigación sobre el origen y destino de las mismas"'. El Tribunal considera que la cuenta es sospechosa pero que no está relacionada con el concreto delito 
de trata investigado que lleva aparejado elevadas penas de prisión "si bien la cuenta es sospechosa ...no aparecen relacionadas con los delitos por los que se solicita una condena de 8 años de prisión, más que en la coincidencia ya expuesta de dos pagos el mismo día de la testigo protegida a la acusada".

Por el contrario, la STS n. 430/2019, de 27 de septiembre recuerda como en ocasiones es imposible seguir el rastro del dinero pagado por la víctima. Para la Sala, la Policía ha investigado una documentación bancaria que revela unos ingresos que ratifica el mecanismo de pago seguido por la víctima "En relación a la documentación bancaria intervenida, se hace constar por el Tribunal que no hace más que ratificar el mecanismo seguido por las víctimas para la entrega de sus ingresos, es decir, mediante ingresos periódicos que de forma inmediata son retirados". El Tribunal entiende que resulta imposible determinar quien realiza los ingresos ya que los pagos se han realizado por cajero "....aun cuando fue objeto de investigación policial, recabándose información en las diferentes entidades bancarias, no ha sido objeto de un profundo estudio contable con identificación precisa de quien efectúa las diferentes imposiciones (lo que por otro lado se presenta como imposible por realizarse en efectivo en diferentes cajeros automáticos)".

También se recalca que al tratarse de un indicio y descansar la prueba de cargo principalmente en las declaraciones de la testigo-víctima, no son necesarios más detalles "pero en la medida que la resolución se basa de forma esencial en la declaración de las testigos protegidas, atribuyéndole a estas pruebas documentales un mero valor de elemento periférico corroborador, consideramos que a pesar de ello poseen el suficiente valor para asumir ese papel secundario que se le asigna".

\subsection{Patrimonio injustificado}

Tiene valor de prueba periférica la posesión por el acusado de un patrimonio que contrasta con los ingresos percibido o con la ausencia de los mismos. Así, para la STS n. 17/2014, de 28 de enero "...la existencia de tres vehículos de los que son titulares, cuando Marisol ha manifestado no trabajar y su compañero Antón solo ha percibido unos ingresos por trabajo los años 2007 y 2009, de 2.857,93 euros; las cargas familiares que soportan, con dos hijos comunes y otra hija de Marisol, que no convivía con ellos y por la que abonaba cantidades mensuales para que otra persona se hiciera cargo de ella, lo que ha sido corroborada por la testifical de esta persona y el otorgamiento de un poder notarial por parte de Marisol que en el juicio afirmó no conocer a dicha persona-, para que se hiciera cargo de su hija". También la Sentencia de la Audiencia Nacional, secc. 4. ${ }^{a}$, n. 1/2015, de 26 de enero describe como "... desde 2.007 a 2.010 los ingresos por rentas del trabajo de A ascienden a la suma global de 23.713,86 € en clara desproporción con los inmuebles adquiridos”. Figuraban inscritos en el Registro de la Propiedad seis inmuebles en varias localidades granadinas por valor de 437.983 euros.

Igualmente la SAP de Sevilla, secc. 4. ${ }^{a}$, n. 1881/2018, de 5 de noviembre concluye como de la documentación que se aporta por los distintos órganos públicos se desprende que los ingresos son escasos e irregulares y que aún así así adquirió un inmueble cuyo valor catastral es de 20.000 euros y el valor de mercado, según la declaración del agente investigador, ronda los 80.000 euros. 
La STS n. 770/2016, de 16 de noviembre descarta la presencia de un patrimonio excesivo. No queda claro, de un lado, que el acusado sea el propietario de la vivienda "el propio acusado ha dicho que es propiedad de un tercero, que entre ellos se avalan para poder comprarse la casa, y por ello nunca ha sido de su propiedad, siendo así que consta en la cuenta de Caixa Catalunya como titulares el acusado y Kangu. Ha dicho que era para pagar la hipoteca de dicha vivienda, pero que quien se hacía cargo de su abono era la otra persona, lo cual no es ilógico y viene corroborado por la cuenta corriente a nombre de ambas personas". El vehículo titularidad del acusado es antiguo “...está matriculado en el año 2001 por lo que tampoco es síntoma de una gran riqueza o manejo de dinero”.

\subsection{Detección de los pagos realizados por la víctima al tratante}

En ocasiones, podrá corroborarse documentalmente el testimonio de la víctima respecto al dinero que ha pagado al tratante. No ocurrirá frecuentemente. Lo lógico es que el esclavista evite dejar pistas documentales claras de su actividad, pero puede suceder como en el caso resuelto por la SAP de Sevilla, secc. 4. ${ }^{\text {a }}$, n. 328/2017, de 4 de julio que la víctima aporte al procedimiento recibos de los pagos hechos a la acusada y en la cuenta corriente de esta última constaban ingresos con el nombre de la víctima como impositora. La justificación de tales pagos “... se erigen en una de las principales corroboraciones de su declaración, habiendo aportado P dos recibos de 500 y 200 euros (obran a los folios 27 y 75 de las actuaciones, realizados respectivamente el 01/08/11 y el 07/09/10) y comprobándose en el extracto de la cuenta bancaria de $\mathrm{U}$ que existen otros muchos ingresos hechos en lunes o martes si era festivo- e incluso que en tres de ellos datados en mayo y junio de 2010, figura como impositor el nombre de P o F (con el que también era conocida, según ella misma aclaró), todos ellos de 200 euros (esos listados obran a los folios 93 y siguientes)". La justificación que se da por la acusada carecía de entidad. Indicó que la víctima le daba el dinero para aportarlo a un fondo constituido semanalmente por nigerianos para ayudarse entre ellos. El Tribunal expone que "resulta contrario a toda lógica si se repara en las elevadas cantidades de que se hablan, que se pretenden aportadas por quien está ejerciendo la prostitución y debe mantener un hijo de corta edad, que más parece necesitada de ayuda que capaz de prestarla". Asimismo, rechaza que el dinero proceda de compras de la víctima en la tienda de la acusada. Las cantidades son elevadas y difícilmente justificables en una situación de penuria económica que no es compatible con comprar productos caros “... que quien ejerce la prostitución para mantenerse y mantener a su hijo destine sus recursos a adquirir productos africanos, lógicamente encarecidos por el transporte hasta España”.

La SAP de Sevilla, secc. 4. ${ }^{\mathrm{a}}$, n. 1881/2018, de 5 de noviembre da por acreditado que la testigo protegida "realizó transferencias bancarias (folios 958, 1229-1269, e informe policial 1862-1880) a favor de L bien a la cuenta corriente de esta o a la de su hija. La acusada no ha justificado razonablemente este extremo y, desde luego, no es posible creer que fuera para el pago de compras que ella realizaba para la TP de objetos, que le mandaba desde Sevilla a Orense por autobús, porque es absurdo cuando no mantenían amistad y ni siquiera se ha presentado documento alguno que justificara que se realizaron esos transportes, lo que podía haber hecho solicitándolo, en todo caso, a la empresa de transporte”.

No solo por vía documental se puede probar que el tratante se queda con el dinero de la víctima. En el caso resuelto por la STS n. 196/2017, de 24 de marzo, los acusados, además de emplear a las víctimas discapacitadas, para diversas labores en una feria, se apropiaron de sus prestaciones por incapacidad. Son los testigos los que permiten corroborar que los 
acusados acompañaban a las víctimas a cobrar la pensión y se quedaban con el dinero "Por último, en lo que se refiere a la sustracción de las pensiones y las ayudas sociales, las cuentas bancarias y libretas de ahorro que se señalan, en defensa del motivo, no acreditan que no se hubieran producido tales sustracciones que vienen sustentadas en las declaraciones depuestas por los perjudicados así como las manifestaciones de testigos que presenciaron las gestiones efectuadas por los acusados para que sus víctimas consiguieran las ayudas que posteriormente iban a hacer suyas".

Los movimientos de dinero procedentes de la víctima se han abordado ocasionalmente desde otra perspectiva. En la SAP de León, secc. 3. ${ }^{a}$, n. 523/2018, de 4 de diciembre, es la defensa la que reclama que se oficie a Correos para que certifique los envíos de la víctima a su país por medio de Western Union. Con ello pretende acreditar que la víctima falta a la verdad cuando dice que por su cautiverio no ha podido mandar dinero a su familia, Correos señala que no puede facilitar ese dato y aporta la dirección de correo electrónico de Western Union a la que el tribunal oficia, pero que no responde a la fecha del juicio. En todo caso, el Tribunal entiende que "las acreditaciones de tales envíos monetarios obedecen a valorar, según la defensa de Norma, si Sandra dice la verdad cuando refiere que bajo su cautiverio no mando dinero a su país, lo que evidentemente no es determinante para concluir, en uno u otro caso, la existencia o no de los delitos por los que han sido acusados".

\subsection{Pagos entre los tratantes}

Otro indicio serán los pagos que se detecten entre esclavistas. El ATS n. 810/2016, de 21 de abril, señala como una madre acusada de vender a su hija a otros tratantes no ha explicado unos ingresos económicos en una cuenta de su hija en la que la acusada figura como autorizada "Tampoco respalda una versión lógica exculpatoria de la acusada, el hecho acreditado de que se produjesen ingresos en una cuenta bancaria a nombre de su hija y con ella en la condición de autorizada, toda vez que de tales ingresos tan solo cabe inferir, tal y como razonablemente ha realizado la Audiencia de Valencia, que eran realizados por la víctima y no por terceras personas, no habiéndose aportado un dato concreto de las mismas, así como tampoco, en razón a qué vínculo familiar o de otro orden con su hija se producían tales ingresos. A todo lo anteriormente reseñado, se une con especial contundencia la declaración de la víctima en el juicio oral, la cual gozó de plena credibilidad para el tribunal sentenciador".

Otro elemento probatorio será la localización de los movimientos de dinero que la sede de la organización en España manda a los captadores en sus países de origen para sufragar los gastos de las mujeres captadas para ser explotadas sexualmente. Un informe del Servicio de Prevención y Blanqueo de Capitales que establece la relación de dinero enviado por los acusados a Paraguay es valorado como indicio por la STS n. 152/2008, de 8 de abril. Dicha Sentencia confirma que dicho informe acceda a juicio por la testifical del policía coordinador de la investigación y del registro y no por quien firma el informe "Y así cita el recurrente el informe del SEPBLAC, sobre relación de cantidades de dinero enviadas a Paraguay, firmado por un instructor que no compareció en el juicio oral, ... la relación de las cantidades de dinero enviadas a Paraguay por las acusadas (informe del SEPBLAC, fo 1018 y 1487) con la finalidad de destinarlas a sufragar los gastos de aquellas mujeres reclutadas en el citado país sudamericano para dedicarlas al ejercicio de la prostitución en el citado local de alterne, explicando que la relación — propuesta como documental por el Ministerio Fiscal en su 
escrito de acusación ( $\mathrm{f}^{\mathrm{O}}$ 97) - accede al juicio mediante el interrogatorio del inspector de Policía coordinador del registro y de la instrucción (f 18 a 24 del acta de la Vista)".

\subsection{Ocupación de elevadas cantidades de dinero en efectivo en poder del tratante}

También integrará una prueba de cargo que confirma la declaración de la víctima encontrar en la detención del acusado o en el registro de su domicilio que disponen de una elevada cantidad de dinero cuyo origen no se justifica. La SAP de Castellón, secc. 2. ${ }^{\text {a }}$, n. 101/2018, de 5 de abril describe como "se ocupó a la tratante en el momento de ser detenida 3.600 euros en metálico y tres cartillas en el bolso a las 9,30 horas". La Sentencia recalca como no vulnera el derecho a la presunción de inocencia que sea el acusado quien deba justificar de donde ha obtenido el dinero cuando puede hacerlo fácilmente "La detenida nunca antes del juicio había dado explicación sobre tal tenencia un tanto insólita. Cuando, aparte de su legítimo derecho a no declarar, razonablemente era exigible una explicación que podía entenderse fácil y razonable si la procedencia fuere lícita y demostrable, no se dió hasta tres años después; y cuando se ha dado, no resulta probada ni verosímil”. La acusada manifestó que ese dinero lo traía de Nigeria para compras por encargo. El Tribunal expone como la acusada falta a la verdad ya que había sacado ese dinero de sus cuentas “...instantes antes de ser detenida se sacaron de unos 1.100 euros y de los otros 2.500 euros. En total 3.600 euros. Suma que coincide con la que llevaba Clara encima. No es cierta la explicación”.

En un supuesto de la trata con fines de mendicidad, en los registros fueron halladas numerosas monedas en metálico lo que es un indicio claro de la realidad de la actividad con la que se explotaba a la víctima. Así, la SAP de Baleares, secc. 2. ${ }^{a}$ n. 359/2017, de 1 de septiembre, señala como "Datos objetivos que corroboran la realidad de los hechos denunciados. En el registro domiciliario fue hallado en la caja fuerte dinero (2.265 euros en billetes) y por la casa una importante cantidad de monedas (31 de 2 euros, 137 de 1 euro, 102 de 50 cts., 139 de 20 cts., 130 de 10 cts. y un bote con monedas de cobre) con un total de 290,80 euros. En el registro en el interior del vehículo utilizado por los acusados fue hallado en el maletero 34 bolsas de plástico con monedas, concretamente 160 de 1 euros, 50 de 2 euros, 180 de 50 cts.,150 de 20 cts. y 100 de 10 cts., con un total de 390 euros". Es de interés, como señala el informe de la policía que la caja fuerte estaba en la habitación del acusado y las monedas por toda la casa salvo en el cuarto donde vivían las víctimas en que no había moneda alguna.

Para el tribunal no hay justificación para la tenencia de cantidades tan importantes de moneda en metálico salvo que procedan del ejercicio de la mendicidad. Se da por probado que el acusado cambió 1.000 levas por moneda "Sin embargo dos personas, que alquilaron vivienda pagando fianza, con gastos, lo razonable es que esas monedas ya las has hubiesen gastado. Podría llevarse dinero en el coche para parking, gasolina, pero el uso de moneda metálica no aparece como propio de un manejo económico normal. Además, tenían dinero en la caja fuerte. La tenencia de tanta moneda metálica casa perfectamente con la obtención de dinero por la mendicidad o la consideración de que al menos parte de ella provenía de la mendicidad".

Por el contrario, la SAP de Sevilla, secc. 4. ${ }^{\mathrm{a}}$, n. 1881/2018, de 5 de noviembre no da valor probatorio a que la Policía acreditara que la acusada había viajado 26 veces a Nigeria en algo más de un año y que en una ocasión fue sorprendida en el aeropuerto de Madrid portando 9.055 euros y el 5 de enero de 2017 llevando 5.000 euros. El Tribunal considera efectiva- 
mente “... que no es razonable que alguien sin especial capacidad económica ni motivos comerciales realice un número tan elevado de viajes" para degradar inmediatamente algo irrazonable a una sospecha insuficiente "...para enervar la presunción de inocencia porque, por una parte, solo se le encontró dinero en dos ocasiones, no pudiendo presuponer que en las otras ocasiones también llevaría sumas importantes de dinero porque así lo habría reseñado la policía; por otra, porque caben explicaciones alternativas para justificar esos viajes, como la que ofreció la procesada que dijo que conocidos le entregaban pequeñas cantidades de dinero para que ella los entregase en Nigeria, y que por ello cobraba una comisión, o, simplemente, que el dinero podía venir de otra actividad ilegal que la procesada no podía descubrir". No comparto el criterio. Ser sorprendido en dos ocasiones con cantidades tan elevadas de dinero es un indicio válido. No es preciso ser sorprendido las 20 veces que viaja a Nigeria. Por otro lado, no se trata de enervar la presunción de inocencia con una prueba principal sino de generar un mero indicio complementario. Asimismo, como hemos visto, la STS n. 430/2019, de 27 de septiembre recuerda que no es admisible que el acusado ofrezca explicaciones generales para justificar la procedencia del dinero. No basta con ensayar explicaciones alternativas, sino que estas deben ser precisas. En este supuesto debiera haberse aportado por la acusada una lista de esos clientes que le entregaban el dinero para llevarlo a Nigeria.

\subsection{La contabilidad de la organización}

Otro caudal probatorio complementario lo constituyen los cuadernos, libretas o documentos que reflejan el pago de la deuda de la víctima al tratante. Es un tipo de contabilidad muy rudimentaria a nivel formal consistiendo en unas cifras, fechas, frecuentemente con tachaduras lo que en nada afecta a su valor como indicio. Como afirma la memoria de la Fiscalía General del año 2019 al señalar, dentro de la red de trata se encuentran los que llevan a cabo "diariamente la contabilidad de los ingresos procedentes de la explotación sexual de las mujeres obligadas a prostituirse distinguiendo a través de una suerte de asientos contables muy rudimentarios las cantidades obtenidas por cada chica; realizar las transferencias a cada controladora o madame; y las entregas a los máximos responsables de la organización, anotando el modo de realizarse el desembolso (efectivo, transferencia bancaria o mediante las denominadas Entidades Gestoras de Fondos _ETF_- )".

El Tribunal Supremo, en diversas resoluciones, confirma su valor probatorio. La STS n. 1171/2009, de 10 de noviembre, alude a la prueba documental consistente en las libretas u otros documentos en los que se llevaba la contabilidad de los servicios o coitos realizados, con liquidación semanal lo que a juicio del Tribunal la participación de la empresa del matrimonio citado en el producto de la prostitución. El ATS n. 1305/2017, de 28 de septiembre refleja también unas cantidades consignadas “...en unas agendas a modo de contabilidad”. La STS n. 482/2016, de 3 de junio, pone de manifiesto como las agendas que la recurrente llevaba en el momento de la detención, reveladora de su actividad delictiva como el nombre de trabajador, el teléfono, datos del empleador y porcentaje que habría de percibir. También la STS n. 52/2006, de 19 de enero, valora como indicio el que "Ángel Jesús y Aurora controlaban, así mismo, bien de forma manuscrita o bien mediante material informático, la contabilidad relativa al pago de las deudas contraídas por las mujeres extranjeras".

Debe destacarse en particular la STS n. 178/2016, de 3 de marzo incide como en uno de los registros domiciliarios se encuentra "Una libreta de naturaleza contable cuya portada presentaba el texto 'School is fun' en cuya redacción intervinieron los procesados ...Una 
libreta con la portada azul y la palabra 'AMIGOS', también de naturaleza contable, redactada íntegramente por el procesado (...) libretas con anotaciones manuscritas en cuya redacción intervinieron los procesados Enrique Salvador y Pelayo Gaspar y que reflejaban los beneficios económicos de la trama procedentes de la explotación sexual de las mujeres a ellos vinculadas". Esta Resolución describe con exactitud la importancia del sistema de contabilidad dentro de la red hasta el punto de que uno de los acusados se dedicaba exclusivamente a esta labor "El procesado desempeñaba en el grupo criminal de referencia, funciones de contable, encargándose de realizar envíos de dinero que le eran ordenados por otros miembros de la trama así como de llevar diariamente la contabilidad de los ingresos procedentes de la explotación sexual de las mujeres obligadas a prostituirse, distinguiendo a través de una suerte de asientos contables muy rudimentarios, las cantidades obtenidas por cada chica, las transferidas a cada controladora o madame, y a su vez las entregadas a los máximos responsables de la trama, especificando si los ingresos se hacían en efectivo, a través de transferencias bancarias o mediante las denominadas Entidades Gestoras de Fondos (E.T.F.) tales como Western Union o similares".

La SAP de Valencia, secc. 2. ${ }^{\text {a }}$, n. 161/2019, de 25 de marzo rechaza el valor de las libretas de contabilidad. De un lado, porque no se corresponden con lo que la víctima declaró que pagó. Ya vimos con anterioridad al comentar esta Sentencia que ello no es necesario pero la Resolución tiene razón en dos aspectos. De un lado, que el Fiscal tiene que aportar el documento contable al procedimiento, proponerlo como prueba documental y exhibirlo el juicio, preguntando al acusado por su autoría y el significado de las cifras o claves que contengan: Expone la Audiencia de Valencia que la libreta no se llevó al juicio por lo que "ninguna pregunta se ha formulado". De otro, reprocha que no se haya explicado al tribunal las cifras y letras que aparecen en el documento. Es importante que el autor del informe financiero explique qué suponen las cifras y otros datos que puedan aparecer en el documento. La Sala indica que "no existe explicación ninguna de las letras que aparecen junto a las cifras, dos iniciales EH, luego $\mathrm{H}$ y luego nada”.

\section{Conclusiones}

Hemos examinado, a través de diversos instrumentos internacionales y sobre todo de la doctrina judicial como la investigación financiera es fundamental para arruinar el negocio de la trata y convertir lo que es un lucrativo negocio en otro ruinoso. Resulta clave la aportación desde el primer instante de la investigación, que se proporcione por las unidades policiales investigadoras de trata las cuentas corrientes de los investigados y los bienes de las que sean titulares con el fin de generar un indicio probatorio complementario. Todo ello sin perjuicio de que se lleven a cabo investigaciones más complejas dirigidas a acreditar un delito de blanqueo o contra la Hacienda Pública.

Asimismo, la prueba financiera, con otros indicios, puede suplir la ausencia de la víctima y sus silencios. Es también importante que los documentos contables de la red se examinan en juicio a los acusados e incorporar un estudio policial sobre su contenido y, en caso de tenerlas, el significado de las claves. 


\section{Bibliografía}

Consejo General del Poder Judicial (2018). Guía sobre criterios de actuación judicial frente a la trata de seres humanos. Bilbao: Consejo General del Poder Judicial.

Defensor del Pueblo (2012). La trata de seres humanos en España: Víctimas invisibles. Madrid: Defensor del Pueblo.

Fernández Olalla, P. (2015). Mesa redonda sobre modos y técnicas de investigación y prueba del delito de trata de seres humanos. Jornada de Técnicas de Investigación del Ministerio Fiscal ( $2^{a}$ edición). Madrid: Ministerio de Justicia.

Fiscalía General del Estado (2015). Memoria. Madrid: Fiscalía General del Estado.

Fiscalía General del Estado (2017). Memoria. Madrid: Fiscalía General del Estado.

Fiscalía General del Estado (2019). Memoria. Madrid: Fiscalía General del Estado.

Jornadas de los Fiscales Delegados de Extranjería (2012). Conclusiones. Madrid: Ministerio de Justicia.

Parlamento Europeo (2016). Resolución del Parlamento Europeo de lucha contra la trata en las relaciones exteriores de la Unión. Bruselas.

United Nations Office on Drugs and Crime (2009). Manual de la investigación contra el delito de trata de personas. Guia de autoaprendizaje. Nueva York: ONU.

United Nations Office on Drugs and Crime (2007). Manual para la lucha contra la trata de personas. Nueva York: ONU. 